\title{
BMJ Open The premature closure of ROMPA clinical trial: mortality reduction in septic shock by plasma adsorption
}

Carola Giménez-Esparza, ${ }^{1}$ Cristina Portillo-Requena, ${ }^{1}$

Francisco Colomina-Climent, ${ }^{2}$ José Manuel Allegue-Gallego, ${ }^{3}$

María Galindo-Martínez, ${ }^{3}$ Cristina Mollà-Jiménez, ${ }^{4}$ José Luis Antón-Pascual, ${ }^{4}$

Enrique Mármol-Peis, ${ }^{4}$ Cristina Dólera-Moreno, ${ }^{4}$ Manuel Rodríguez-Serra, ${ }^{5}$

José Luis Martín-Ruíz, ${ }^{5}$ Pablo Juan Fernández-Arroyo, ${ }^{6}$

Eugenia María Blasco-Císcar, ${ }^{6}$ José Cánovas-Robles, ${ }^{7}$

Enrique González-Hernández, ${ }^{8}$ Fernando Sánchez-Morán, ${ }^{8}$ Manuel Solera-Suárez, ${ }^{9}$ Jesús Torres-Tortajada, ${ }^{9}$ Antonio Palazón-Bru (10 , ${ }^{2}$ Vicente F Gil-Guillen ${ }^{2}$

To cite: Giménez-Esparza C Portillo-Requena C, ColominaCliment $\mathrm{F}$, et al. The premature closure of ROMPA clinical trial: mortality reduction in septic shock by plasma adsorption. BMJ Open 2019;9:e030139. doi:10.1136/ bmjopen-2019-030139

- Prepublication history for this paper is available online. To view these files, please visit the journal online (http://dx.doi. org/10.1136/bmjopen-2019030139).

Received 28 February 2019 Revised 17 October 2019 Accepted 24 October 2019

Check for updates

(c) Author(s) (or their employer(s)) 2019. Re-use permitted under CC BY-NC. No commercial re-use. See rights and permissions. Published by BMJ.

For numbered affiliations see end of article.

Correspondence to

Professor Antonio Palazón-Bru; antonio.pb23@gmail.com

\section{ABSTRACT}

Objectives Coupled Plasma Filtration and Adsorption (CPFA) use in septic shock remains controversial. The objective is to clarify whether the application of high doses of CPFA in addition to the current clinical practice could reduce hospital mortality in septic shock patients in Intensive Care Units at 28 days and at 90 days followup.

Design We designed a prospective randomised clinical trial, Reducción de la Mortalidad Plasma-Adsorción (ROMPA), to demonstrate an absolute mortality reduction of $20 \%(\alpha=0.05 ; 1-\beta=0.8 ; n=190(95 \times 2)$ ).

Setting Being aware of the pitfalls associated with previous medical device trials, we developed a training programme to improve CPFA use (especially clotting problems). The protocol was approved by the ethics committees of all participating centres. Circumstances beyond our control produced a change in recruitment conditions unacceptable to ROMPA researchers and the trial was discontinued.

Participants By closure, five centres from an initial 10 fulfilled the necessary trial criteria, with 49 patients included, 30 in the control group (CG) and 19 in the intervention group (IG).

\section{Intervention CPFA}

Main outcome measures Hospital mortality at 28 days and 90 days follow-up.

Results After 28 days, 14 patients died (46.7\%) from the CG and $11(57.9 \%)$ from the IG, not reaching statistical significance $(p=0.444)$. At 90 days, 19 patients had died (63.3\%) from the $\mathrm{CG}$ and 11 patients (57.9\%) from the IG, $(p=0.878)$. The adjustment by propensity score or the use of the Kaplan-Meier technique failed to achieve statistical difference, neither by Intention to Treat nor by the Actual Intervention Received.

Conclusion We herewith present the results gained from the prematurely closed trial. The results are inconclusive due to low statistical power but we consider that this data is of interest for the scientific community and potentially necessary for any ensuing debate.

Register NCT02357433 in clinicaltrials.gov.
Strengths and limitations of this study

- Randomised control clinical trial testing the efficacy of Coupled Plasma Filtration and Adsorption in septic shock.

- Premature closure due to circumstances beyond the control of the trial.

- Scarce sample size: underpowered trial.

\section{INTRODUCTION}

Sepsis is still a leading cause of mortality in Intensive Care Unit (ICU) patients, with a $20 \%-50 \%$ mortality rate from sepsis and septic shock. ${ }^{1}$ There has been a feeling of frustration generated by the large amount of negative randomised clinical trials (RCTs) in septic shock treatment (especially in those targeting mortality) over the past 30 years. ${ }^{2}$ Patients included in these trials vary widely in their probability of death. This translates into differences in the benefits derived from specific therapy application, which in turn handicaps sample size calculation. This can lead to the trial having less statistical power than initially planned, increasing the risk of a type two error and this is the origin of unexpected results. ${ }^{3}$ It questions the use of subgroups in an attempt to extract some kind of useful information in negative RCTs. ${ }^{4}$

The COMPACT 1, a multicentre RCT study, failed to show any benefits when using Coupled Plasma Filtration and Adsorption (CPFA) therapy in a population with septic shock. In a per-protocol analysis, patients treated with CPFA using a volume of treated plasma superior to $0.20 \mathrm{~L} / \mathrm{kg} /$ day demonstrated a reduction in mortality 
rate. ${ }^{5}$ Although an interesting result, our group considered it was necessary to carry out an RCT to confirm this hypothesis.

The response to this question was Reducción de la Mortalidad Mediante Plasma-Adsorción (ROMPA) en Shock séptico, a multicentre RCT carried out in ICUs of southeastern Spain. The ROMPA Study (NCT02357433 in clinicaltrials.gov) tried to clarify whether the application of high doses of CPFA in addition to the current clinical practice was able to reduce hospital mortality in septic shock patients in ICUs. The protocol of ROMPA has been published in a free access journal and the details of the protocol can be consulted without restrictions. ${ }^{6}$

In October 2017, the trial investigators of COMPACT 2 (NCT01639664 in clinicaltrials.gov), a similar study to ROMPA conducted in Italian ICUs, ${ }^{7}$ reported the premature closure of the study for having detected an increase in early mortality (three first days) in the intervention branch $(6 / 42(12.5 \%)$ vs $19 / 58(32.8 \%) \mathrm{p}=0.020$, not reaching the 350 patient sample size prefixed in the protocol). The adjusted OR of the treatment yielded by logistic regression is 2.1 (95\% CI: 0.7 to $6.6, p=0.19)$ and the adjusted HR yielded by the Cox model is $2.5(95 \%$ CI: 1.4 to $4.4, p=0.002)$. This information was immediately reported to our Ethical Committee and these results were published on the research group website in Italian. ${ }^{8}$ Subsequent events, including a provisional warning by the product supplier, led us to close ROMPA. At that time, of the 10 initial hospitals, only five had exceeded the technical capacity requirements and availability of resources required to access the randomisation portal. Due to the severity of the events, our group wishes to show the data collected so far and the results from the 49 enrolled patients (30 control and 19 intervention groups).

\section{METHODS}

\section{Protocol}

The full study protocol has been published previously. ${ }^{6}$ In this section, a synthesis of the protocol is given (Methods).

\section{Setting and participants}

The study was performed in five ICUs in the southeast of Spain, all following the same protocol in the treatment of septic shock, which is based on the recommendations of the Surviving Sepsis Campaign. The following centres participated: Vega Baja Hospital of Orihuela, General University Santa Lucía Hospital of Cartagena, University Hospital of San Juan de Alicante, Lluís Alcanyís Hospital of Xàtiva and Francesc de Borja Hospital of Gandía.

The ROMPA study is a multicentre, randomised, prospective, open clinical trial with 28-day and 90-day follow-up and allocation ratio 1:1, assessing the mortality reduction by CPFA in patients with septic shock. Furthermore, we analysed 3-day mortality to compare our results with the Italian group.

Each centre obtained technical proficiency with the machine and CPFA treatment before they could become 'activated' for enrolment by the investigator-monitoring team. This was done, first, in order to avoid similar problems as those reported in the first COMPACT study (coagulation of the extracorporeal circuit; technical problems intimately linked to the management of a complex extracorporeal circuit; logistical problems which required an extracorporeal technique such as CPFA; problems related to the need for specialised personnel). ${ }^{4}$ Second, as CPFA is not routinely administered in Spain, a new machine with improved anticoagulation support was developed and used for this trial.

\section{Participants}

Patients $\geq 18$ years-old with a diagnosis of septic shock and admitted to the ICU of the participant hospitals are eligible to be included in the study. Diagnosis of septic shock was defined as documented or suspected infection with systemic manifestations of infection accompanied by signs of organ failure, or tissue hypoperfusion with persistent hypotension despite administration of adequate fluid resuscitation (at least $30 \mathrm{~mL} / \mathrm{kg}$ crystaloides) and in the absence of other causes of hypotension. The inclusion and exclusion criteria are detailed in the published protocol. ${ }^{6}$

\section{Interventions}

The patient is registered once the informed consent form has been obtained by the patient or legal representative. The recruitment process ends with the patient randomisation. The time between septic shock diagnosis and randomisation was established in 12 hours, because this window adjusts much more to the reality of the clinical situation, at least that of the hospitals that participated in the ROMPA study. The researchers of the COMPACT two study reached the same conclusion. ${ }^{7}$

Patients were divided randomly into two arms (control and intervention). ROMPA has a stratified randomisation based on gender, age ( $\leq 65$ or $>65$ years) and Simplified Acute Physiology Score III (SAPS III) score $(<50$ or $\geq 51)$. On the one hand, in the control group we followed the suggestions provided by the recent surviving sepsis guidelines, as well as standard care guidelines typically followed in Spain. On the other hand, in the CPFA group, we applied the same protocol plus high doses of CPFA in the first 3 days after randomisation.

\section{Variables and measurements}

\section{Primary and secondary outcomes}

The primary outcome variable is all-cause mortality assessed at 28 and 90 days after the recruitment of the patient. The analysis of 3-day mortality, although not initially specified in the protocol, was an added recommendation by our Ethical Committee once the data of the Italian group had become known. ${ }^{8}$

Moreover, at the descriptive level and in order to check homogeneity of both groups, the following variables will be collected at the time of recruitment: birth year, gender, height, dry weight, body temperature, heart rate, blood 


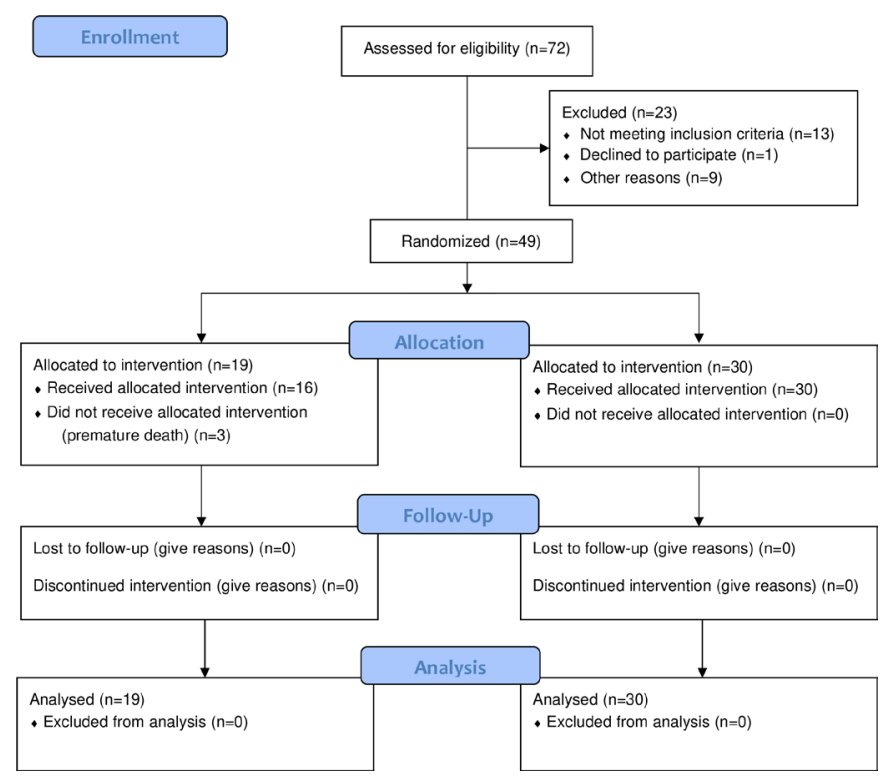

Figure 1 Flow chart of the clinical trial (partial results).

pressure, blood cell count, coagulation values, glucose level, plasma creatinine, bilirubinemia, plasma $\mathrm{C}$ reactive protein, procalcitonin level, blood gas analysis, lactate, urinary output (mL/kg/hour), $\mathrm{PaO}_{2} / \mathrm{FiO}_{2}$ ratio, Acute Physiology And Chronic Health Evaluation II (APACHE II), Sequential Organ Failure Assessment and SAPSIII scores.

\section{Sample size}

Originally, a sample size of 190 patients was calculated to determine differences in mortality rates in both groups with a power-of-contrast of $80 \%$. The assumed control group mortality rate was $50 \%$ and we tried to demonstrate a reduction in mortality of $20 \%$ in the intervention group (similar to the COMPACT I results). ${ }^{4}$ A partial analysis with the first 49 patients has been carried out as described in this paper. Using the data from the initial sample size calculation, these patients represent an approximate power-of-contrast of $30 \%$.

\section{Statistical analysis}

Initially, the calculation of the indicators of clinical relevance (relative risk, absolute risk reduction (ARR), relative risk reduction, number needed to treat, by intent to treat (ITT) was planned. Without having the sample size calculated for the study (intermediate analysis) and having made the allocation based on a set of variables, the homogeneity of the groups could not be established. The propensity scores as a population overlap weight technique was applied with the objective of overcoming the problem caused by the lack of homogeneity between the two groups. ${ }^{9}$ The adjustment variables were APACHE II, previous lactate levels and the presence of urinary sepsis. Finally, although not established in the study protocol, Kaplan-Meier survival curves were analysed to determine differences in mortality in the analysed groups (log-rank test). Since a significant number of patients died in the
Table 1 Comparison between the intervention and the control group

\begin{tabular}{lccc}
\hline Variable & $\begin{array}{l}\text { Control } \\
\text { group } \mathbf{n = 3 0} \\
\mathbf{n}(\%) / \mathbf{x} \pm \mathbf{s}\end{array}$ & $\begin{array}{l}\text { CPFA } \mathbf{n = 1 9} \\
\mathbf{n}(\%) / \mathbf{x} \pm \mathbf{S}\end{array}$ & P value \\
\hline Gender male & $18(60.0)$ & $11(57.9)$ & 0.884 \\
\hline Abdominal sepsis & $12(40.0)$ & $8(42.1)$ & 0.884 \\
Cancer & $11(36.7)$ & $7(36.8)$ & 0.990 \\
\hline $\begin{array}{l}\text { Community-acquired } \\
\text { pneumonia }\end{array}$ & $5(16.7)$ & $3(15.8)$ & $>0.999$ \\
Nosocomial & $3(10.0)$ & $3(15.8)$ & 0.665 \\
pneumonia & $9(30.0)$ & $5(26.3)$ & 0.781 \\
\hline Diabetes & $8(26.7)$ & $3(15.8)$ & 0.492 \\
\hline Urinary sepsis & $28.9 \pm 5.6$ & $27.0 \pm 5.1$ & 0.244 \\
APACHE II & $12.8 \pm 3.3$ & $12.2 \pm 4.4$ & 0.541 \\
\hline SOFA & $74.5 \pm 20.9$ & $70.7 \pm 21.0$ & 0.587 \\
\hline SAPS II & $5.3 \pm 3.4$ & $5.9 \pm 4.1$ & 0.580 \\
\hline Lactate (mmol/L) & $70.0 \pm 13.6$ & $71.0 \pm 14.5$ & 0.812 \\
\hline Age (years) & & & \\
\hline
\end{tabular}

APACHE, Acute Physiology And Chronic Health Evaluation; CPFA, Coupled Plasma Filtration Adsorption; $n(\%)$, absolute frequency (relative frequency); SAPS, Simplified Acute Physiology Score; SOFA, Sequential Organ Failure Assessment; $x \pm S$, mean $\pm S D$.

first 3 days and were unable to receive the technique $(\mathrm{n}=3,15.8 \%)$ we decided to perform the analysis by actual intervention received (AIR). Although this analysis was not initially planned (clinicaltrials.gov), the fact that one out of six patients did not receive the intervention necessitated it.

\section{Ethical issues}

There was a general agreement that the trial closure was the best option, since the decision adopted by the Italian group to close its trial had been made public through its website resulting in the device supplier marking their product used for the test with a warning. A Data and Safety Monitoring Board was set up to periodically review and evaluate the study data for the safety of the patients. It was formed by the Principal Investigator, the Senior Investigator and the Biostatistician of the project.

\section{Patient and public involvement}

This research was done without patient involvement. Patients were not invited to comment on the study design and were not consulted to develop patient relevant outcomes or interpret the results. Patients were not invited to contribute to the writing or editing of this document for readability or accuracy.

\section{RESULTS}

A total of 49 patients were included in the final analysis (30 in the control group and 19 in the intervention group) (figure 1). The randomisation tables are displayed 


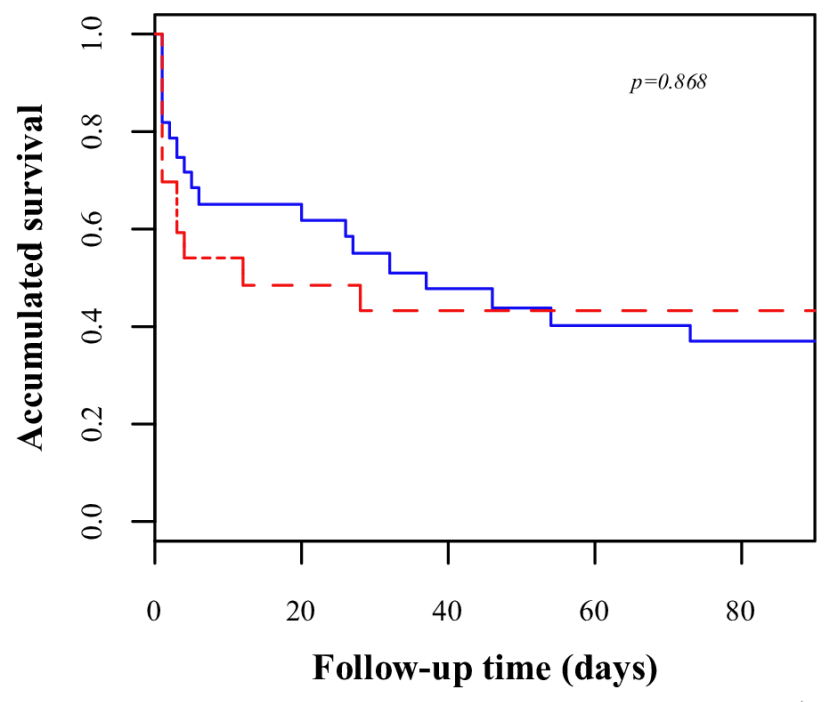

A

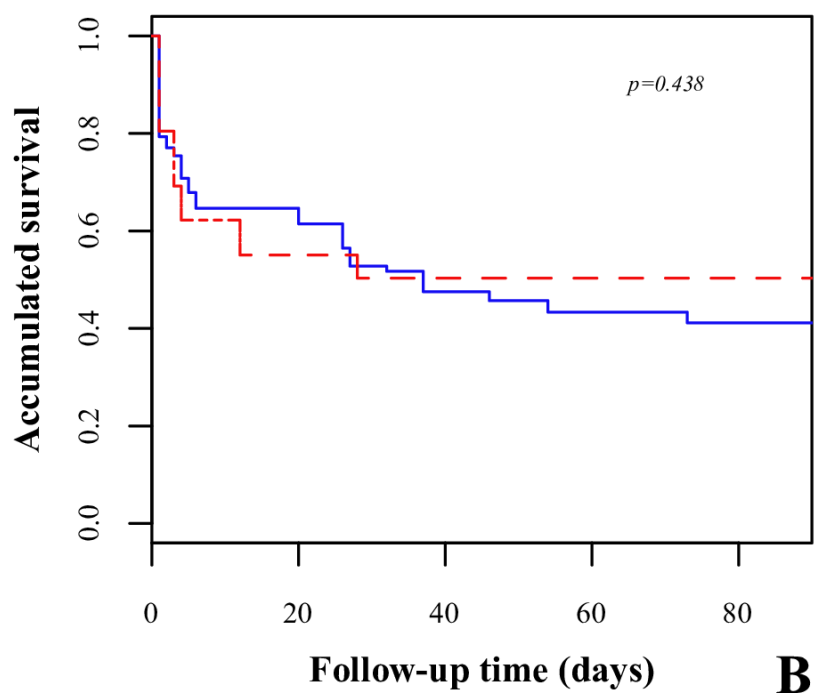

Figure 2 Survival analysis using the Kaplan-Meier estimator comparing both groups. Red, intervention; blue, control. A, intention to treat; $\mathrm{B}$, real intervention.

in table 1. Parametric statistics did not allow us to establish significant differences between the analysed factors due to the small sample size. However, we can see a mean difference between the two groups based on three variables: 1.9 on an APACHE II score, $0.6 \mathrm{mmol} / \mathrm{L}$ of lactate levels and $10.9 \%$ in the prevalence of urinary sepsis. All these factors have been used in the propensity score test.

With regard to mortality (without adjusting by propensity score), seven patients $(23.3 \%)$ had died in the first 3 days from the control group and eight patients $(40.6 \%)$ had died from the intervention group $(\mathrm{p}=0.146)$. After 28 days, 14 patients had died $(46.7 \%)$ from the control group and 11 patients had died $(57.9 \%)$ from the intervention group, not reaching statistical significance $(\mathrm{p}=0.444)$. At 90 days 19 patients had died $(63.3 \%)$ from the control group and 11 patients had died (57.9\%) from the intervention group, which is to say no patient died from the intervention group between 28 and 90 days $(\mathrm{p}=0.878$ ). Adjusting by propensity score and using the Kaplan-Meier technique (figure 2), statistical significant difference was not reached, neither by ITT (table 2) nor by the AIR. (table 3 ).

In patients who died in the first 3 days, we found that the base-line levels of lactate were higher compared with the rest of the patients (in $\mathrm{mmol} / \mathrm{L}$ ): $7.96 \pm 4.79$ versus $4.43 \pm 2.41, p=0.015$. A similar situation was revealed in the APACHE score: $29.7 \pm 5.1$ versus $27.5 \pm 5.5, \mathrm{p}=0.194$, although this variable was not significant.

\section{DISCUSSION \\ Summary}

Our results seem to indicate that the patients who received CPFA had less chance of mortality in the long term (90 days), whether by ITT analysis or AIR analysis. However, in the short and medium term during ITT analysis, CPFA had a detrimental effect and when using AIR analysis the effect was protective. In any case, the statistical power to obtain conclusions from these results was low and therefore non-significant. As a consequence, we are only describing the estimation of the analysed parameters (HR and proportions).

\section{Limitations of the study}

This RCT was designed to determine medium and longterm differences between CPFA and standard care. For this purpose, a sample size of 190 patients was predetermined. In these partial results, the sample size of 190 was not reached due to the cessation of the trial and therefore the statistical power of the comparison contrast is very low $(\sim 30 \%)$. As a consequence, the ARR of $20 \%$ is much too high and unrealistic. Combined with the low sample size, this yields a very low statistical power. In addition, as the randomisation process was undertaken based on the baseline characteristics of the patient, this can produce differences between the groups. Moreover, we can observe that the sample sizes of the two groups are not similar (the control group has approximately $50 \%$ more patients). All this has led to the use of propensity score adjustment in order to obtain results similar to an RCT (homogeneous groups, except in the intervention received). ${ }^{9}$ However, even if we apply this technique we still have a low power of contrast. Despite this limitation, we are obliged to communicate our partial results following the premature closure of the RCT COMPACT 2.

\section{Comparison with the existing literature}

We agreed with the Ethics Committee to review the incidence of early mortality in our trial after the findings communicated to us by the COMPACT 2 team. It should be emphasised that the ROMPA investigators were not given any impression of these COMPACT 2 findings during the ROMPA clinical trial. The results reported by the group of researchers of COMPACT 2 here deserve 
Table 2 Clinical relevance of the intervention (intention-to-treat) in the patients with septic shock (adjusted by propensity scores as a population overlap weight)

\begin{tabular}{llllll}
\hline Outcome & RR $(\mathbf{9 5} \% \mathbf{C l})$ & RRR $(\mathbf{9 5 \%} \mathbf{C l})$ & ARR (95\% Cl) & NNT/NNH* & P value \\
\hline 3-day mortality & $1.67(0.51$ to 5.46$)$ & $-0.67(-4.46$ to 0.49$)$ & $-0.17(-0.54$ to 0.20$)$ & $6(\mathrm{H})$ & 0.667 \\
28-day mortality & $1.28(0.57$ to 2.87$)$ & $-0.28(-1.87$ to 0.43$)$ & $-0.13(-0.53$ to 0.28$)$ & $8(\mathrm{H})$ & 0.537 \\
90-day mortality & $0.92(0.48$ to 1.76$)$ & $0.08(-0.76$ to 0.52$)$ & $0.05(-0.35$ to 0.45$)$ & $19(\mathrm{~T})$ & $>0.999$ \\
\hline
\end{tabular}

*Not possible to compute the $\mathrm{Cl}$ (division by zero).

ARR, Absolute Risk Reduction;H, Harm; NNH, Number Needed to Harm; NNT, Number Needed to Treat; RR, relative risk; RRR, Relative Risk Reduction; T, Treat.

a special mention. ${ }^{8}$ In these results, as occurred in our group, a preliminary analysis was developed that is far from the sample size initially calculated and therefore with low statistical power of contrast (not indicated by them in their report). In addition, as in our study, the COMPACT 2 group used a randomisation system based on prognostic scores, ${ }^{6}$ which means that the groups will not be similar until the end of recruitment (which is reason to introduce the propensity score in our results).

In this situation, subgroup analysis has the problem of introducing analytic challenges and can lead to overstated and misleading results, ${ }^{10}$ and, as such, we have to consider the remarkably low mortality of the control group, together with a remarkably high mortality of the intervention group. These results seem to be far removed from those that are obtained in usual clinical practice. This situation was not observed in the first COMPACT trial $^{5}$ and we have not heard of a retrospective analysis to explain these results.

Lastly, we would like to comment on the margin of time chosen by the Italian group to carry out its partial results. We think it is important to assess the patient's mortality, but this mortality should be assessed with a global calculation. For a technique to be effective, it must decrease the patient's mortality in a reasonable period of time in order to allow the healing of sepsis and its possible consequences. For this reason, the periods of 28 days and 90 days were fixed by our protocol. Consequently, for the sake of conducting an effective clinical trial, it is not of relevance that the patient dies early, but whether the patient dies in a period of time where he has a high mortality risk due to sepsis. Additionally, in the calculation of the sample size of the Italian group, mortality at 3 days was not contemplated and could be a result of either random error or heterogeneous groups in the treatment allocation. At this point, it must be stated that the ROMPA investigators are not at any moment criticising the COMPACT 2 decision to halt their trial. ROMPA's researchers remain aware of the complexity of such a decision and that it involves multiple factors, the most important being the security of the patients.

\section{Implications to research}

Our study was halted prematurely for the reasons we have previously explained when only 49 patients had been randomised (out of a target 190 patients). In the intervention arm, 19 patients were randomised and 30 patients in the control arm. In both approaches (ITT and real intervention), we have not found evidence of either benefit or harmful effect in the tested treatment and, of course, this comes as no surprise due to the premature termination.

At this level of recruitment and with a statistical power of $30 \%$, our sample is exposed to the random effect, resulting in a lack of homogeneity in the levels of basal risk. This lack of homogeneity predetermines that the technique can be presented as either beneficial or harmful. In fact the technique appears less beneficial in the subgroup (not predefined) of patients who died in 72 hours and these were patients with an elevated basal risk, primarily expressed through lactate levels and APACHE 2 score.

We would like to comment on a controversial issue. Three patients who had been randomised to the intervention group (20\%) died in the first 72 hours and did not receive the CPFA treatment. The rapid haemodynamic deterioration of the patients did not allow the connection to the extracorporeal circuit. Undoubtedly, adequate sample size management minimised this problem, but if what we are considering is the potential harmfulness of the technique in a non-prespecified subgroup of an

Table 3 Clinical relevance of the intervention (real group) in the patients with septic shock (adjusted by propensity scores as a population overlap weight)

\begin{tabular}{lllllr}
\hline Outcome & RR $(\mathbf{9 5} \% \mathbf{C l})$ & RRR $(\mathbf{9 5 \%}$ Cl) & ARR (95\% Cl) & NNT* & P value \\
\hline 3-day mortality & $0.84(0.26$ to 2.73$)$ & $0.16(-1.73$ to 0.74$)$ & $0.06(-0.32$ to 0.44$)$ & 18 & $>0.999$ \\
\hline 28-day mortality & $0.93(0.42$ to 2.06$)$ & $0.07(-1.06$ to 0.58$)$ & $0.04(-0.37$ to 0.45$)$ & 26 & $>0.999$ \\
\hline 90-day mortality & $0.72(0.35$ to 1.48$)$ & $0.28(-0.48$ to 0.65$)$ & $0.19(-0.21$ to 0.59$)$ & 6 & 0.417 \\
\hline
\end{tabular}

${ }^{\star}$ Not possible to compute the $\mathrm{Cl}$ (division by zero).

ARR, Absolute Risk Reduction; NNT, Number Needed to Treat; RR, relative risk; RRR, Relative Risk Reduction. 
underpowered sample size, we cannot ignore the fact that the technique was not applied.

\section{CONCLUSIONS}

In this paper we have presented the results of the 49 patients randomised in our trial up until the moment of closure. As a consequence of the procedure being underpowered, it was not possible to do an analysis of contrast of hypothesis and under this inconvenience, we present the results obtained for the interest of all who are concerned about what happened in our trial. When all is taken into consideration, we have not found a difference in mortality between the two groups.

\section{Author affiliations}

${ }^{1}$ Intensive Care Unit, Vega Baja Hospital of Orihuela, Orihuela, Alicante, Spain ${ }^{2}$ Department of Clinical Medicine, Miguel Hernández University, San Juan de Alicante, Alicante, Spain

${ }^{3}$ Intensive Care Unit, General University Santa Lucía Hospital of Cartagena, Cartagena, Murcia, Spain

${ }^{4}$ Intensive Care Unit, University Hospital of San Juan de Alicante, San Juan de Alicante, Alicante, Spain

${ }^{5}$ Intensive Care Unit, Lluís Alcanyís Hospital of Xàtiva, Xàtiva, Valencia, Spain

${ }^{6}$ Intensive Care Unit, Marina Baixa Hospital of Villajoyosa, Villajoyosa, Alicante, Spain

${ }^{7}$ Intensive Care Unit, General University Hospital of Alicante, Alicante, Alicante, Spain

${ }^{8}$ Intensive Care Unit, La Plana Hospital of Villarreal, Villarreal, Castellón, Spain

${ }^{9}$ Intensive Care Unit, Francesc de Borja Hospital of Gandía, Gandía, Valencia, Spain

Twitter Francisco Colomina-Climent @pacocolomina1, José Luis Antón-Pascual @ joseluisanton3 and Fernando Sánchez-Morán @Fredomoran

Acknowledgements The authors thank all the health professionals integrated in the ROMPA research group and those who have participated in our study.

Contributors CG-E designed the study and drafted the paper of the protocol; CP-R participated in the study design and helped draft the paper; FC-C, JMA-G, MG-M, CM-J, JLA-P, EM-P, CD-M, MR-S, JLM-R, PJF-A, EMB-C, JC-R, EG-H, FS-M, MS-S, JT-T and VFG-G participated in the study design and reviewed critically the manuscript; AP-B participated in the study design, performed the statistical analysis and reviewed critically the manuscript. All the authors approved the final version of the text to be submitted for publication.

Funding This work was supported by Bellco, who provided all the devices and materials related to the use of CPFA for the treatment group. This entity did not play any role in study design; collection, management, analysis and interpretation of data; writing of this report; the decision to submit this report for publication.

Competing interests None declared.
Patient consent for publication Not required.

Ethics approval The study was originally approved by all Ethics Committees of the Hospitals participating in the study.

Provenance and peer review Not commissioned; externally peer reviewed.

Data availability statement Data are available upon reasonable request.

Open access This is an open access article distributed in accordance with the Creative Commons Attribution Non Commercial (CC BY-NC 4.0) license, which permits others to distribute, remix, adapt, build upon this work non-commercially, and license their derivative works on different terms, provided the original work is properly cited, appropriate credit is given, any changes made indicated, and the use is non-commercial. See: http://creativecommons.org/licenses/by-nc/4.0/.

ORCID iD

Antonio Palazón-Bru http://orcid.org/0000-0002-5959-9631

\section{REFERENCES}

1 Gaieski DF, Edwards JM, Kallan MJ, et al. Benchmarking the incidence and mortality of severe sepsis in the United States. Crit Care Med 2013;41:1167-74.

2 Opal SM, Dellinger RP, Vincent J-L, et al. The next generation of sepsis clinical trial designs: what is next after the demise of recombinant human activated protein C ${ }^{\star}$. Crit Care Med 2014;42:1714-21.

3 Wong JLC, Mason AJ, Gordon AC, et al. Are large randomised controlled trials in severe sepsis and septic shock statistically disadvantaged by repeated inadvertent underestimates of required sample size? BMJ Open 2018;8:e020068.

4 Vincent J-L, Marini JJ, Pesenti A. Do trials that report a neutral or negative treatment effect improve the care of critically ill patients? no. Intensive Care Med 2018;44:1989-91.

5 Livigni S, Bertolini G, Rossi C, et al. Efficacy of coupled plasma filtration adsorption (CPFA) in patients with septic shock: a multicenter randomised controlled clinical trial. BMJ Open 2014;4:e003536.

6 Colomina-Climent F, Giménez-Esparza C, Portillo-Requena C, et al. Mortality reduction in septic shock by plasma adsorption (rOmpA): a protocol for a randomised clinical trial. BMJ Open 2016;6:e011856.

7 Gruppo Italiano per la Valutazione degli Interventi in Terapia Intensiva. COMPACT-2: combining Plasmafiltration and adsorption clinical Trial-2. Available: http://www.giviti.marionegri.it/COMPACT2. asp [Accessed 27 Nov 2018].

8 Gruppo Italiano per la Valutazione degli Interventi in Terapia Intensiva. Chiusura anticipata dello Studio COMPACT-2. Available: http:// www.giviti.marionegri.it/Download/COMPACT-2\%20Chiusura\% 20anticipata.pdf [Accessed 27 Nov 2018].

9 Stuart BL, Grebel LE, Butler CC, et al. Comparison between treatment effects in a randomised controlled trial and an observational study using propensity scores in primary care. $\mathrm{Br} \mathrm{J}$ Gen Pract 2017;67:e643-9.

10 Wang R, Lagakos SW, Ware JH, et al. Statistics in medicine-reporting of subgroup analyses in clinical trials. N Engl J Med 2007;357:2189-94. 
Correction: The premature closure of ROMPA clinical trial: mortality reduction in septic shock by plasma adsorption

Giménez-Esparza C, Portillo-Requena C, Colomina-Climent F, et al. The premature closure of ROMPA clinical trial: mortality reduction in septic shock by plasma adsorption. BMJ Open 2019;9:e030139. doi: 10.1136/bmjopen-2019-030139.

This article was previously published with an error.

The following statement in the discussion section is incorrect: 'In addition, as in our study, the COMPACT 2 group used a randomisation system based on prognostic scores, ${ }^{6}$ which means that the groups will not be similar until the end of recruitment (which is reason to introduce the propensity score in our results).' The COMPACT 2 group used a blocked randomization schedule (randomly permuting blocks of four and six), with stratification according to site and the presence of septic shock at admission.

Open access This is an open access article distributed in accordance with the Creative Commons Attribution Non Commercial (CC BY-NC 4.0) license, which permits others to distribute, remix, adapt, build upon this work non-commercially, and license their derivative works on different terms, provided the original work is properly cited, appropriate credit is given, any changes made indicated, and the use is non-commercial. See: http://creativecommons.org/licenses/by-nc/4.0/.

(C) Author(s) (or their employer(s)) 2020. Re-use permitted under CC BY-NC. No commercial re-use. See rights and permissions. Published by BMJ.

BMJ Open 2020;10:e030139corr1. doi:10.1136/bmjopen-2019-030139corr1

D) Check for updates 